\title{
Indacaterol and salmeterol in COPD patients: a comparative study of efficacy and safety
}

\author{
Bhanu P. Kolasani ${ }^{1}$, Raghunandan Mudium $^{2}$, Sudheer Diyya ${ }^{3}$
}

${ }^{1}$ Department of Pharmacology, Rajiv Gandhi Institute of Medical Sciences, Putlampalli, Kadapa, Andhra Pradesh, India ${ }^{2}$ Department of Pharmacology, Raichur Institute of Medical Sciences, Raichur, Karnataka, India

${ }^{3}$ Department of Pulmonology, Rajiv Gandhi Institute of Medical Sciences, Putlampalli, Kadapa, Andhra Pradesh, India

Received: 19 May 2013

Accepted: 8 June 2013

*Correspondence to:

Dr. Bhanu P. Kolasani,

Email:

kolasanibhanu@yahoo.co.in

(C) 2013 Kolasani BP et al. This is an open-access article distributed under the terms of the Creative Commons Attribution License, which permits unrestricted use, distribution, and reproduction in any medium, provided the original work is properly cited.

\begin{abstract}
Background: Chronic obstructive pulmonary disease (COPD) is an airway disorder characterized by airflow limitation that is not fully reversible. Indacaterol is a novel, inhaled, once-daily, ultra-long-acting $\beta 2$-agonist bronchodilator recently approved in India for the treatment of chronic obstructive pulmonary disease (COPD). The aim of the present study was to investigate the efficacy and safety of indacaterol compared to twice-daily $\beta 2$ agonist, salmeterol, as an active control.

Methods: The present study was open, randomized parallel group comparison of two active treatment groups over a 12 week period. A total of 60 patients with moderate-to-severe COPD were randomised to treatment either with indacaterol (150 $\mu \mathrm{g}$ once daily) or with salmeterol (50 $\mu \mathrm{g}$ twice daily) and 51 $(85 \%)$ patients completed the study. The efficacy parameters were change in FEV1, health related quality of life by measuring St George's Respiratory Questionnaire (SGRQ) total score and severity of dyspnoea as measured by Transition Dyspnoea Index (TDI) score which were assessed at baseline first and at weeks 4,8 and 12 .

Results: Indacaterol increased FEV1 at week 4 by $50 \mathrm{ml}$, at week 8 and at week 12 by $60 \mathrm{ml}$ over salmeterol and the increase was highly significant $(\mathrm{p}<0.001)$ at all stages of the study. Both treatments improved health status (SGRQ total score) and dyspnoea (TDI score), with differences between them favouring indacaterol. Safety profiles were similar across the treatment groups, and both indacaterol and salmeterol were well tolerated without any severe adverse events.

Conclusions: Once-daily treatment with $150 \mu \mathrm{g}$ indacaterol had a significant and clinically relevant bronchodilator effect and improved health status and dyspnoea to a greater extent than twice-daily $50 \mu \mathrm{g}$ salmeterol. Indacaterol should prove a useful addition in the treatment of patients with COPD.
\end{abstract}

Keywords: Bronchodilator, Chronic obstructive pulmonary disease, St George's Respiratory Questionnaire, Transition Dyspnoea Index

\section{INTRODUCTION}

Chronic obstructive pulmonary disease (COPD) is characterized by airflow limitation that is not fully reversible. COPD is estimated to affect $10 \%$ of the world's population aged $\geq 40 \mathrm{yrs}$, and prevalence is expected to continue to increase over coming years. ${ }^{1}$ COPD is a major public health problem worldwide and is expanding throughout with a higher prevalence, morbidity and mortality rate. The World Health Report2002 listed COPD as the fifth leading cause of death. ${ }^{2}$ It currently ranks number 6 in global disease impact scale and is predicted to rise to number three by $2020 .^{2}$ The prevalence of COPD in India is 5\% in males and $2.7 \%$ in females, with the male to female ratio of $1.6: 1 .^{3}$ It translates into approximately 12 million cases in India alone. The incidence and prevalence of COPD is increasing as a result of urban ambient air pollution and indoor exposure concentrations of particulate air pollution. ${ }^{4,5,6}$

Regular treatment with one or more long-acting inhaled bronchodilators is an important and recommended element in managing the symptoms of patients with 
COPD. ${ }^{7}$ These agents are either $\beta_{2}$-agonists administered twice daily (formoterol and salmeterol) or the once-daily anticholinergic, tiotropium. Long acting $\beta 2$-agonists like salmeterol and formoterol are commonly used and usually are administered twice daily because their duration of action is nearly 12 hours. Indacaterol is a new inhaled ultra-long-acting $\beta 2$-agonist bronchodilator that has duration of action of 24 hours and so can be administered once daily. ${ }^{8}$

It was recently approved in the India at two doses, 150 and $300 \mu \mathrm{g}$ once daily, for use in the maintenance treatment of patients with COPD. There were some studies done comparing the efficacy and safety of indacaterol with other long acting bronchodilators in the western literature ${ }^{9,10}$ but till date, there was no study done in India. The present study is designed to compare the efficacy and safety of the new drug ultra long-acting $\beta 2$ agonist indacaterol with the established long-acting $\beta 2$ agonist bronchodilator salmeterol.

\section{METHODS}

\section{Patients}

The study was conducted on a total of 60 patients with a clinical diagnosis of moderate-to-severe $\mathrm{COPD}^{7}$ attending the outpatient department of Pulmonology of our institute. Only male patients aged more than $40 \mathrm{yrs}$ and a smoking history of more than 10 pack-years were enrolled in the study. Spirometry test results at screening were forced expiratory volume in $1 \mathrm{~s}(\mathrm{FEV} 1)<80 \%$, an increase in $\mathrm{FEV}_{1}$ with the use of $200 \mu \mathrm{g}$ of salbutamol of $<12 \%$ of the predicted value for that patient and FEV1/forced vital capacity $<0.7$. The response to inhaled bronchodilator of more than $12 \%$ was taken to discriminate asthma from COPD. Patients with history of asthma, unstable respiratory status, recent respiratory infection, continuous daily oxygen requirement, congestive cardiac failure and uncooperative patients were excluded from the study

\section{Study Design}

The present study is a randomized, open, parallel group comparative clinical study between once daily indacaterol and twice daily salmeterol and in patients with moderateto-severe COPD conducted at department of Pulmonology, Rajiv Gandhi Institute of Medical Sciences, Kadapa. The duration of the study is 3 months from December, 2012 to February, 2013. The study was approved by Institute Ethical Committee and procedures followed in this study are in accordance with the ethical standard laid down by ICMR's ethical guidelines for biomedical research on human subjects (2006). A written informed consent was obtained from all the patients who participated in the study after explaining the patient's diagnosis, the nature and purpose of a proposed treatment, the risks and benefits of the proposed treatment (indacaterol/salmeterol), alternative treatment and the risks and benefits of the alternative treatment. Following a 2-week run-in and screening period, during which baseline variables were assessed and concomitant medication stabilised, patients were randomised by using computer generated random list. After randomization, the patients were divided into two treatment groups. A total of 30 patients were allocated in the indacaterol group who received indacaterol $(150 \mu \mathrm{g}$ once daily via singledose dry-powder inhaler, taken in the morning) and another 30 patients in the salmeterol group who received salmeterol (50 $\mu \mathrm{g}$ twice daily (morning and evening) via its proprietary dry powder inhaler) for 12 weeks. As use of inhaler is technique dependent, the inhaler technique was taught to each patient. Dose and regimen remained stable throughout the study. Patients previously on fixed combinations of ICS and long-acting $\beta 2$-agonist were switched to the equivalent ICS monotherapy, at a dose and regimen that was maintained throughout the study. Salbutamol was provided for use as needed (but not $<6 \mathrm{~h}$ before study assessments).

\section{Efficacy and Safety Variables}

The efficacy variables were change in FEV1, health status and severity of dyspnoea which were assessed at baseline first and at weeks 4, 8 and 12. The measurement of FEV1 was done by a Maestros spirometer where flow measurements were done by using Terbium followed by computerized analysis. FEV1 was done before giving study drugs and atleast one hour after the study drugs are taken, usually after 5 minutes after taking the study drugs.

Health status was assessed by St George's Respiratory Questionnaire (SGRQ) ${ }^{11}$, which is a standardized selfadministered airways disease-specific questionnaire that provides an overall measure for quality of life with subscale scores in three areas: Symptom, activity, and impact of disease on daily life. It contains 50 items (covering 76 levels) divided into three subscales: "Symptoms" (8 items), including several respiratory symptoms, their frequency and severity; "Activity" (16 items), concerned with activities that cause or are limited by breathlessness; and "Impacts" (26 items), which covers a range of aspects concerned with social functioning and psychological disturbances resulting from airways disease. Each item in the questionnaire has a weight attached, which provides an estimate of the distress associated with the symptom or state described. A score was calculated for each subscale of the SGRQ and also an overall score was calculated. SGRQ scores range from 0-100, with score 0 indicating no impairment of life quality and 100 indicating maximum disability. The questionnaire has been shown to be reproducible and valid. We adapted the English language of the SGRQ as received and doctors' local language was used while interpreting the questionnaires and aimed to reflect the usual language of the patients. The minimum clinically important difference (MCID) was four points in SGRQ total score. $^{12}$ 
Dyspnoea was assessed at baseline as the baseline dyspnoea index, which provides a multidimensional measurement of dyspnea based on 3 components that evoke dyspnea in activities of daily living- functional impairment, magnitude of task and magnitude of effort. Each component is rated in five grades from 0 (very severe) to 4 (no impairment) and the score can range from 0 to 12 . The lower the score, the worse the severity of dyspnea. Dyspnoea was also assessed at weeks 4, 8 and 12 as the transition dyspnoea index (TDI) ${ }^{13}$, which measures changes in dyspnea severity from the baseline as established by the BDI for the same three components. It is rated by seven grades ranging from -3 (major deterioration) to +3 (major improvement). Here, the total score ranges from -9 to +9 . The lower the score, the more deterioration in severity of dyspnea, with a change of one point regarded as the MCID. ${ }^{14}$

Safety and tolerability was assessed in terms of reported adverse experiences and vital signs, which were measured at baseline and at each clinical visit. At each clinic visit, adverse events were recorded and vital signs were monitored All reported adverse drug events were graded according to The National Cancer Institute Common Toxicity Criteria (CTC) and compared between the groups. ${ }^{15}$

\section{Statistical Methods}

All statistical calculations were done by paired t-test, unpaired t-test, and Fischer's exact test . A P value of < 0.05 was considered statistically significant and a $\mathrm{P}$ value of $<0.001$ as highly significant. Considering FEV1 as the primary outcome, the sample size has been calculated taking the level of significance $(\alpha)$ as 0.05 , power of the study $(1-\beta)$ as 0.80 , and expected mean difference 1.25 . Raw mean (nonadjusted) data are also presented for the changes from baseline in TDI and SGRQ scores.

\section{RESULTS}

\section{Patient Disposition and Baseline Demographics}

A total of 90 patients were assessed for eligibility following inclusion and exclusion criteria. Among them, 19 patients were excluded because they did not meet the inclusion criteria and another 11 patients declined to participate in the study. So finally a total of 60 patients were randomized to two groups to receive either indacaterol $(n=30)$ or salmeterol $(n=30)$. Table 1 shows the demographics and baseline characteristics in both the treatment groups and they were comparable in all the aspects without any significant difference. In total, post baseline values were missing in 9 patients. One patient from indacaterol group was lost at week 8 and three did not turn up for end of the study visit (week 12); whereas from salmeterol group, two patients were lost at week 8 and three did not turn up for last visit. Figure 1 shows the flow of patients through various stages of the study.
Table 1: Demographics and baseline characteristics in both the treatment groups.

\begin{tabular}{|lll|}
\hline Parameter & $\begin{array}{l}\text { Indacaterol } \\
\text { group }(\mathbf{n}=26)\end{array}$ & $\begin{array}{l}\text { Salmeterol } \\
\text { group }(\mathbf{n}=\mathbf{2 5})\end{array}$ \\
\hline $\begin{array}{l}\text { Age in years, } \\
\text { mean } \pm \text { SD }\end{array}$ & $61.3 \pm 9.12$ & $60.9 \pm 8.44$ \\
\hline $\begin{array}{l}\text { Years of symptoms, } \\
\text { mean } \pm \text { SD }\end{array}$ & $5.14 \pm 2.97$ & $5.16 \pm 2.62$ \\
\hline $\begin{array}{l}\text { Smoking history } \\
\text { Nonsmoker(\%) } \\
\text { Smoker(\%) }\end{array}$ & $2(6.6)$ & $1(3.33)$ \\
\cline { 2 - 3 } FEV1, mean \pm SD & $1.28 \pm 0.25$ & $1.34 \pm 0.28$ \\
\hline $\begin{array}{l}\text { SGRQ total score, } \\
\text { mean } \pm \text { SD }\end{array}$ & $46 \pm 16.8$ & $45 \pm 16.6$ \\
\hline BDI score & $6.8 \pm 2.1$ & $6.7 \pm 2.2$ \\
\hline COPD severity staging & $25(83.3)$ & $27(90)$ \\
\hline $\begin{array}{l}\text { Moderate }(\%) \\
\text { Severe }(\%)\end{array}$ & $5(16.7)$ & $3(10)$ \\
\hline
\end{tabular}

SD: standard deviation; COPD: chronic obstructive pulmonary disease; FEV1: forced expiratory volume in 1 s; FVC: forced vital capacity; SGRQ: St George's Respiratory Questionnaire; BDI: baseline dyspnoea index. Values in parenthesis indicate percentages.

\section{Spirometry (FEV1)}

Figure 2 shows the change in the FEV1 at weeks 4, 8 and 12 in both treatment groups. In indacaterol group, the increase in the FEV1 was $110 \mathrm{ml}, 150 \mathrm{ml}$ and $160 \mathrm{ml}$ from its baseline value whereas in salmeterol group, the increase was $60 \mathrm{ml}, 90 \mathrm{ml}$ and $100 \mathrm{ml}$ from baseline value respectively for weeks 4,8 and 12. The change in FEV1 was significantly greater with indacaterol than with salmeterol at all weeks $(\mathrm{p}<0.001)$. An advantage of 50-60 $\mathrm{mL}$ for indacaterol over salmeterol at the $5 \mathrm{~min}$ after dose time-point was observed at all the remaining clinical visits.

\section{SGRQ Total Scores}

The unadjusted mean SGRQ total scores with indacaterol and salmeterol are given in Table 2. It can be observed from the table that the scores have been decreased (i.e. improved health status) from baseline by more than the four-point minimum clinically important difference at all visits. The changes in adjusted mean SGRQ total score compared with the baseline value for indacaterol group ( $6.0,-7.3$ and -8.1 at weeks 4,8 and 12) and for salmeterol group (-4.1, -5.1 and -5.2 at weeks 4,8 and 12) were all significant $(\mathrm{p}<0.05)$ throughout the study (Figure 3$)$. The negative sign for the change in the SGRQ scores merely show that they are decreased from their baseline values. The difference between indacaterol group and salmeterol group in relation to the change in the SGRQ total score was significant $(\mathrm{p}<0.05)$ only at week 12 . 


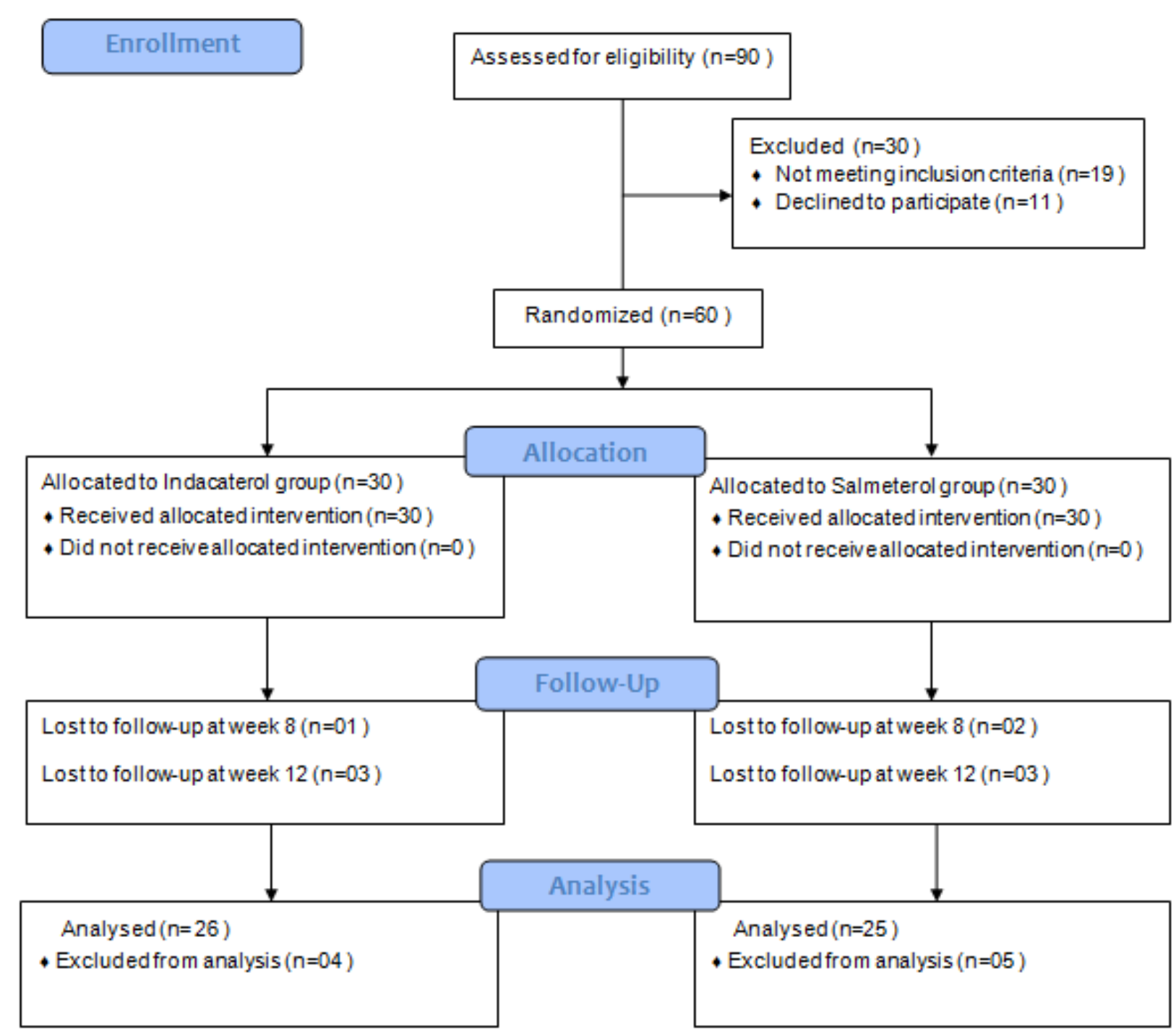

Figure 1: CONSORT flow diagram of patients.

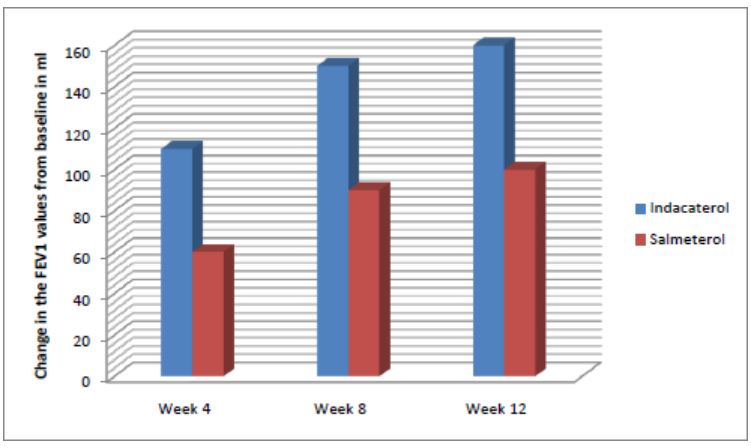

FV1: forced expiratory volume in $1 \mathrm{~s}$

Figure 2: Change in the FEV1 values from their baseline values.
Table 2: Unadjusted mean SGRQ total scores in indacaterol group and salmeterol group.

\begin{tabular}{|lll|}
\hline Week & $\begin{array}{l}\text { Indacaterol } \\
\text { group(n=26) } \\
(\text { Mean } \pm \text { SD) }\end{array}$ & $\begin{array}{l}\text { Salmeterol } \\
\text { group }(\mathbf{n = 2 5}) \\
\text { (Mean } \pm \text { SD) }\end{array}$ \\
\hline 0 ( Baseline) & $46 \pm 16.8$ & $45 \pm 16.6$ \\
\hline 4 & $40 \pm 15.5^{*}$ & $41 \pm 15.1^{*}$ \\
\hline 8 & $39 \pm 14.9^{*}$ & $40 \pm 15.2^{*}$ \\
\hline 12 & $38 \pm 14.1^{*}$ & $40 \pm 14.4^{*}$ \\
\hline
\end{tabular}

SD: Standard deviation; SGRQ: St George's Respiratory Questionnaire

* All values have a Minimum Clinically Important Difference (MCID) when compared to their baseline values 


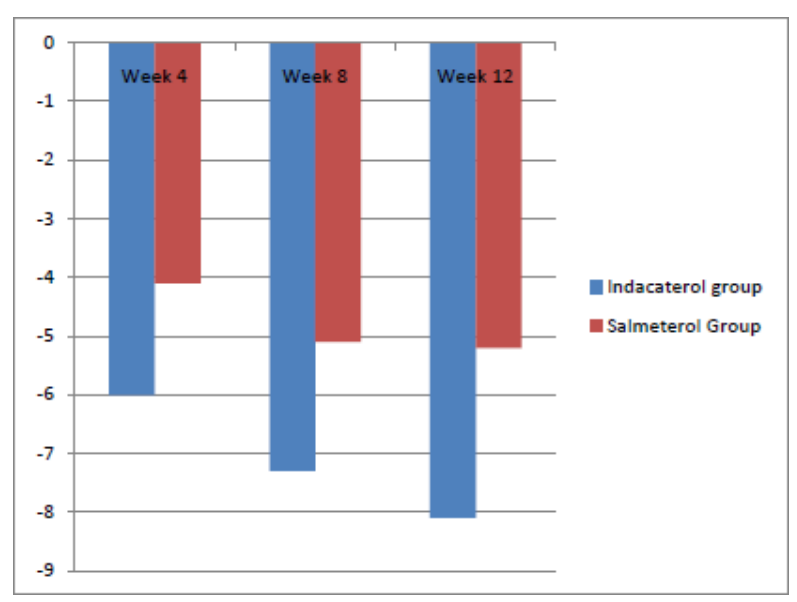

SGRQ: St George's Respiratory Questionnaire

Negative values indicate a decrease in the scores (Improved health status)

\section{Figure 3: Change in the SGRQ total scores from baseline values.}

\section{TDI Scores}

Table 3 shows the unadjusted mean change from baseline in TDI total score at weeks 4,8 and 12 . These scores were higher than their baseline values with both salmeterol $(\mathrm{p}<0.05)$ and indacaterol $(\mathrm{p}<0.001)$ at all visits. The mean differences from their baseline values were numerically larger with indacaterol than with salmeterol, significantly $(\mathrm{p}<0.05)$ so at weeks $4(2.0$ versus 1.4) and 12 (2.4 versus 1.9) (Figure 4).

Table 3: Unadjusted mean change from baseline in TDI total score.

\begin{tabular}{|lll|}
\hline Week & $\begin{array}{l}\text { Indacaterol* } \\
(\mathbf{n = 2 6 )} \\
(\text { mean } \pm \text { SD })\end{array}$ & $\begin{array}{l}\text { Salmeterol }^{\dagger} \\
(\mathbf{n = 2 5}) \\
(\text { mean } \pm \text { SD })\end{array}$ \\
\hline 4 & $2.01 \pm 0.35^{\ddagger}$ & $1.41 \pm 0.32^{\ddagger}$ \\
\hline 8 & $2.12 \pm 0.41$ & $1.83 \pm 0.43$ \\
\hline 12 & $2.43 \pm 0.49^{\ddagger}$ & $1.91 \pm 0.38^{\ddagger}$ \\
\hline
\end{tabular}

SD: Standard deviation; TDI: Transition dyspnoea Index * Values are highly significant $(\mathrm{p}<0.001)$ when compared with their baseline values

${ }^{\dagger}$ Values are significant $(\mathrm{p}<0.05)$ when compared with their baseline values

t Values are significant $(\mathrm{p}<0.05)$ when compared between the two groups

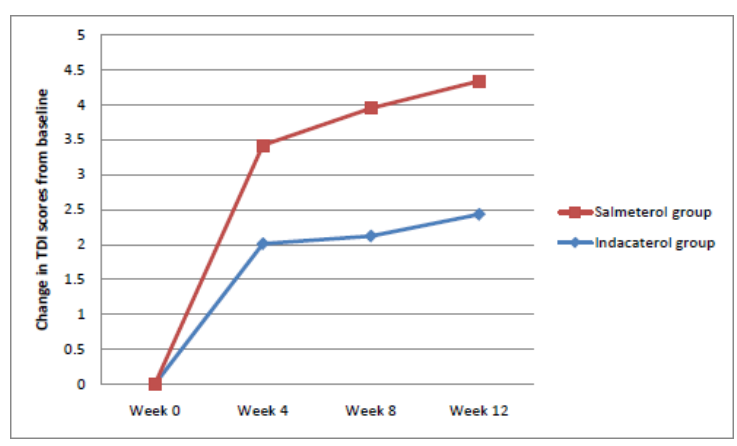

TDI: Transition dyspnoea index

Figure 4: Change in the TDI scores from their baseline values.

\section{Safety and Tolerability}

Table 4 shows the comparative incidence of adverse events in both the treatment groups. Those events that might be considered to be typically $\beta 2$-adrenoceptormediated were rarely reported (tremor, one patient in each of the indacaterol and salmeterol groups; tachycardia, one patient treated with indacaterol). As an adverse event, cough was the most commonly reported by $30.7 \%$ of indacaterol-treated patients and $36 \%$ of salmeterol- treated patients. In the majority of cases, this cough started within $15 \mathrm{~s}$ of inhalation and had a median duration of $12 \mathrm{~s}$. The cough was not associated with bronchospasm, increased study discontinuation rates, or loss of bronchodilator efficacy. The other adverse effects were nasopharyngitis, headache, upper respiratory infection and back pain.

Table 4: Comparative incidence of adverse events in both the treatment groups.

\begin{tabular}{|lll|}
\hline $\begin{array}{l}\text { Adverse } \\
\text { Event }\end{array}$ & $\begin{array}{l}\text { Indacaterol } \\
\text { group }(\mathbf{n = 2 6})\end{array}$ & $\begin{array}{l}\text { Salmeterol } \\
\text { group }(\mathbf{n = 2 5})\end{array}$ \\
\hline Cough & $8(30.7)$ & $9(36)$ \\
\hline Nasopharyngitis & $3(11.5)$ & $3(12)$ \\
\hline Headache & $2(7.7)$ & $5(20)$ \\
\hline URTI & $2(7.7)$ & $3(12)$ \\
\hline Tremor & $1(3.8)$ & $1(4)$ \\
\hline Tachycardia & $1(3.8)$ & $0(0)$ \\
\hline Back pain & $0(0)$ & $1(4)$ \\
\hline
\end{tabular}

URTI: Upper respiratory tract infection; Values in parenthesis indicate percentages

\section{DISCUSSION}

Similar to the way in which the twice-daily $\beta 2$-agonist bronchodilators were shown to be more effective treatments for COPD patients than more frequently dosed short-acting bronchodilators ${ }^{9,16}$, in this 3-month 
comparison, a once daily $\beta 2$-agonist was generally expected to be more effective than a twice daily agent. Comparing the bronchodilator effect, FEV1 was significantly higher with indacaterol than with salmeterol at all visits during the whole study period and there was no loss of bronchodilator effect over the course of the study

The effect of salmeterol on FEV1 was similar to that observed in other studies. ${ }^{17-19}$ The additional efficacy of $50-60 \mathrm{~mL}$ provided by indacaterol over salmeterol is similar to the margin provided by once-daily tiotropium over salmeterol. ${ }^{20}$ The choice of FEV1 as a primary efficacy parameter is relevant to COPD patients, given that the early morning is when COPD patients report symptoms to be at their worst and when they have difficulty accomplishing activities. ${ }^{20}$ The additional improvement in airflow with indacaterol at this time, both before and just after dosing, may help patients start to undertake their morning activities. The effects of indacaterol monotherapy on morning lung function appear similar to previous findings with combined bronchodilator treatment. ${ }^{21}$ All the values of increased FEV1 due to indacaterol at all visits of this study prove that once-daily $150 \mu \mathrm{g}$ indacaterol is a more effective bronchodilator than twice-daily $50 \mu \mathrm{g}$ salmeterol.

Indacaterol-treated patients reported improved health status as measured by SGRQ total score relative to its baseline value, by a margin that was more than the MCID for this measure at all points of study. Salmeterol had a lesser, but still significant, effect. The difference in the SGRQ between indacaterol and salmeterol was significant $(\mathrm{p}<0.05)$ only at the end of the study (week 12). The effect of indacaterol and salmeterol on dyspnoea followed a pattern similar to that of the health status results. Both treatments were more effective, with indacaterol reaching statistical significance versus salmeterol at weeks 4 and 12. This was observed even though salmeterol had a larger effect on dyspnoea ${ }^{17,18,22}$ and health status ${ }^{17,23}$ than in previous studies. Reasons for the differences are unclear and do not appear to be due to differences in COPD severity. The effects of indacaterol on these end points were consistent with those seen at the 6-month time point in other studies. ${ }^{9,10}$ Breathlessness is considered the most disabling symptom for the COPD patient $\mathrm{t}^{24}$, and a sustained reduction in dyspnoea is an important finding for indacaterol. Indacaterol also allowed patients more days without recourse to salbutamol use and they were better able to undertake usual activities, compared with salmeterol.

FEV1 was chosen as the first important parameter because this is mainly a comparison of bronchodilator treatment for COPD patients. The time duration of study (12 weeks) was also according to the reference standards. Health status which was assessed by SGRQ total score and dyspnoea index are more relevant to everyday clinical practice and from the patient's point of view.
Safety and tolerability were similar across the treatment groups, and the greater efficacy and duration of bronchodilator effect of indacaterol was not reflected in any increase in $\beta 2$-mediated effects relative to salmeterol. Similar observations were made in a 1-yr study employing higher doses (300 and $600 \mu \mathrm{g}$ ) of indacaterol. ${ }^{9}$ Although, there were minor side effects seen in both the groups, no patient had severe and unacceptable adverse effect during the during the entire study. An acceptable safety profile is especially important for a treatment designed for chronic use by COPD patients, who tend to be elderly and often have comorbidities, the most important being cardiovascular conditions, lung cancer and osteoporosis. ${ }^{25-27}$

Cough immediately following indacaterol inhalation has been reported previously. ${ }^{28,29}$ Cough following inhalation was fairly common, but did not appear troublesome to patients. It did not result in any loss of efficacy (comparison of the change from baseline in FEV1 showed similar or greater increases in patients who coughed compared with those who did not), nor was it associated with bronchoconstriction or withdrawal from the study.

\section{CONCLUSIONS}

This study shows that once daily indacaterol is a more effective bronchodilator than twice daily salmeterol and that indacaterol improved health status and reduced dyspnoea better than the currently available bronchodilator agent, salmeterol in respect to improving clinical outcomes in moderate to severe COPD patients. These findings suggest that once-daily indacaterol will be a useful additional option for treating this disabling condition, although larger studies involving more number of patients should be done.

\section{ACKNOWLEDGEMENTS}

We specially thank Mr. Rangaswamy, Biostatistician, department of community medicine for providing the statistical analysis for the study data and also the patients who participated in this study for their kind co-operation.

Funding: None

Conflict of interests: None declared

Ethical approval: The study was approved by the Institutional Ethics Committee

\section{REFERENCES}

1. Mannino DM, Buist AS. Global burden of COPD: risk factors, prevalence, and future trends. Lancet 2007; 370: 765-773.

2. Vermeire P. The burden of chronic obstructive pulmonary disease. Respir Med 2002;96:S3-10.

3. Jindal SK, Aggarwal AN, Gupta D. A review of population studies from India to estimate national burden of chronic obstructive pulmonary disease and its association with smoking. Indian J Chest Dis Allied Sci 2001;43:139-47. 
4. Sunyer J, Schwartz J, Tobias A, Macfarlane D, Garcia J, Anto JM. Patients with chronic obstructive pulmonary disease are at increased risk of death associated with urban particle air pollution: A casecrossover analysis. Am J Epidemiol 2000;151:50-6.

5. Smith KR, Mehta S. The burden of disease from indoor air pollution in developing countries: Comparison of estimates. Int J Hyg Environ Health 2003;206:279-89.

6. Chhabra SK, Chhabra P, Rajpal S, Gupta RK. Ambient air pollution and chronic respiratory morbidity in Delhi. Arch Environ Health 2001;56:58-64.

7. Global Initiative for Chronic Obstructive Lung Disease. Global Strategy for the Diagnosis, Management, and Prevention of Chronic Obstructive Pulmonary Disease. www.goldcopd.com/ GuidelineItem.asp?intId=1386 Date last accessed: January 17, 2010. Date last updated: 2009.

8. Feldman G, Siler T, Prasad N, et al. Efficacy and safety of indacaterol 150 microg once-daily in COPD: a double-blind, randomised, 12-week study. BMC Pulm Med. 2010;10:11

9. Dahl R, Chung KF, Buhl R, et al. Efficacy of a new once-daily LABA, indacaterol, versus the twicedaily LABA, formoterol, in COPD. Thorax. 2010;65:473-479.

10. Donohue JF, Fogarty C, Lötvall J, et al. INHANCE Study Investigators. Once-daily bronchodilators for chronic obstructive pulmonary disease: indacaterol versus tiotropium. Am J Respir Crit Care Med. 2010;182:155-162.

11. Jones PW, Quirk FH, Baveystock CM, et al. A selfcomplete measure of health status for chronic airflow limitation. The St. George's Respiratory Questionnaire. Am Rev Respir Dis 1992; 145: 1321-1327.

12. Jones PW. St. George's Respiratory Questionnaire: MCID. COPD 2005; 2: 75-79.

13. Mahler DA, Weinberg DH, Wells CK, et al. The measurement of dyspnea. Contents, interobserver agreement, and physiologic correlates of two new clinical indexes. Chest 1984; 85: 751-758.

14. Witek TJ Jr., Mahler DA. Minimal important difference of the transition dyspnoea index in a multinational clinical trial. Eur Respir J 2003; 21: 267-272.

15. Common Toxicity Criteria (CTC) Version 2.0. Available from: http://ctep.cancer.gov/protocoldevelopment/electron ic_applications/docs/ctcv20_4-30-992.pdf. [Last accessed on 1999 Apr 30].

16. Mahler DA, Donohue JF, Barbee RA, et al. Efficacy of salmeterol xinafoate in the treatment of COPD. Chest 1999; 115: 957-965.
17. Hodder R, Kesten S, Menjoge S, et al. Outcomes in COPD patients receiving tiotropium or salmeterol plus treatment with inhaled corticosteroids. Int J Chron Obstruct Pulmon Dis 2007; 2: 157-167.

18. Donohue JF, van Noord JA, Bateman ED, et al. A 6month, placebo-controlled study comparing lung function and health status changes in COPD patients treated with tiotropium or salmeterol. Chest 2002; 122: 47-55.

19. Hanania NA, Darken P, Horstman D, et al. The efficacy and safety of fluticasone propionate (250 $\mu \mathrm{g}) /$ salmeterol $(50 \mu \mathrm{g})$ combined in the Diskus inhaler for the treatment of COPD. Chest 2003; 124 : 834-843.

20. Partridge MR, Karlsson N, Small IR. Patient insight into the impact of chronic obstructive pulmonary disease in the morning: an internet survey. Curr Med Res Opin 2009; 25: 2043-2048.

21. Welte T, Miravitlles M, Hernandez P, et al. Efficacy and tolerability of budesonide/formoterol added to tiotropium in patients with chronic obstructive pulmonary disease. Am J Respir Crit Care Med 2009; 180: 741-750.

22. ZuWallack RL, Mahler DA, Reilly D, et al. Salmeterol plus theophylline combination therapy in the treatment of COPD. Chest 2001; 119: 16611670.

23. Calverley P, Pauwels R, Vestbo J, et al. Combined salmeterol and fluticasone in the treatment of chronic obstructive pulmonary disease: a randomised controlled trial. Lancet 2003; 361: 449-456.

24. Celli BR, Cote CG, Marin JM, et al. The body-mass index, airflow obstruction, dyspnea, and exercise capacity index in chronic obstructive pulmonary disease. N Engl J Med 2004; 350: 1005-1012.

25. Sin DD, Anthonisen NR, Soriano JB, et al. Mortality in COPD: role of comorbidities. Eur Respir J 2006; 28: 1245-1257.

26. Barnes PJ, Celli BR. Systemic manifestations and comorbidities of COPD. Eur Respir J 2009; 33: 1165-1185.

27. Huiart L, Ernst P, Suissa S. Cardiovascular morbidity and mortality in COPD. Chest 2005; 128 : 2640-2646.

28. Rennard S, Bantje T, Centanni S, et al. A doseranging study of indacaterol in obstructive airways disease, with a tiotropium comparison. Respir Med 2008; 102: 1033-1044.

29. Beier J, Chanez P, Martinot JB, et al. Safety, tolerability and efficacy of indacaterol, a novel once-daily b2-agonist, in patients with COPD: a 28day randomised, placebo controlled clinical trial. Pulm Pharmacol Ther 2007; 20: 740-749.

doi:10.5455/2319-2003.ijbcp20130815

Cite this article as: Kolasani BP, Mudium R, Diyya

S. Indacaterol and salmeterol in COPD patients: a comparative study of efficacy and safety. Int J Basic Clin Pharmacol 2013;2:421-7. 